\title{
ESTUDIOS
}

\section{Territorios, mapas, y reconfiguraciones musicales desde el Sur. Para pensar un jazz latinoamericano}

Territories, maps, and musical reconfigurations from the South. Thinking about Latin American jazz

\author{
por \\ Berenice Corti \\ Instituto de Investigación en Etnomusicología, \\ Ministerio de Cultura, Buenos Aires. Argentina. \\ berenice.corti@gmail.com
}

\begin{abstract}
El artículo da cuenta del pasaje del concepto de latin jazz, acuñado en Estados Unidos para describir los cruces entre el jazz y la "música latina", a la idea en construcción de un jazz latinoamericano, surgido de los estudios respecto de las escenas musicales en expansión del continente.

Palabras clave: Jazz latinoamericano, identidad, Atlántico Negro.
\end{abstract}

This article gives an account of the passage of Latin Jazz concept, originated in the United States to describe the crossings between jazz and 'Latin Music', to the idea in construction of a Latin American Jazz, emerged from the studies on expansive musical scenes of the continent.

Keywords: Latin American jazz, identity, Black Atlantic.

En abril de 2012 se realizó en Córdoba, Argentina, el I Simposio "Jazz en América Latina” en el marco del X Congreso de la Asociación Internacional para el Estudio de la Música Popular, Rama Latinoamericana (IASPM-AL). El objetivo fue avanzar en el intercambio de experiencias y estudios pertinentes al jazz de la región, proceso ya iniciado en 2010 con la constitución del Grupo de Trabajo homónimo de esta Asociación. Así como fue expresado en la convocatoria del simposio, se trató de emprender la construcción de una mirada local acerca de las propias prácticas que estuviera inscripta en un marco conceptual también localmente situado.

Los antecedentes de estas iniciativas pueden rastrearse en los debates concernientes a la llamada identidad de la música de jazz en América Latina -y sus marcas de nacionalidad o regionalidad-, que adquirieron una notable visibilidad en los últimos años tanto en los campos artísticos de distintos países como en 
publicaciones académicas ${ }^{1}$. Muchas de esas preocupaciones continuaron presentes en los trabajos presentados en el simposio.

Para mencionar a algunos de esos debates se puede citar al historiador musical argentino Sergio Pujol², quien al preguntarse por la existencia de un jazz argentino argumentó que la cuestión no podría resolverse "con un mero inventario de argentinismos" incorporados al discurso musical. La utilización de elementos musicales reconocibles como "argentinos" no garantizaría entonces la existencia de un nuevo estilo: "en todo caso, estamos ante un abanico de estrategias sonoras más o menos novedosas (...) y músicos argentinos que se preguntan, a la hora de tocar, qué cosas los vinculan y qué cosas los diferencian de músicos de otros lugares”. En el interés de acceder a los procesos de producción de esas estrategias, propuse hace algunos años un análisis poiético de los sentidos de identidad construidos por algunos músicos argentinos de jazz ${ }^{3}$. Se trataba de exceder el clásico registro de las referencias nacionalizadas presentes en la superficie significante musical para proponer un análisis que fuera más allá de su sola invocación, que hasta el momento bastaba ya -desde un criterio claramente esencialista- para garantizar la identidad musical. De esta forma, pensar la identidad como un proceso inacabado de producción de sentido que incluye sus condiciones de producción y los modos en que es construido, hace inscribir al análisis más allá de lo sígnico musical posibilitando el acceso a una construcción política y performática de ese "jazz argentino", atendiendo a las especificidades de sus distintas estrategias con sus significaciones particulares ${ }^{4}$.

En Brasil, Acácio Piedade indagó en el funcionamiento discursivo del jazz de su país sirviéndose de su propia noción de musicalidad como conjunto de elementos musicales y simbólicos, profundamente interconectados, que constituyen el sistema regulador del mundo musical de una comunidad específica ${ }^{5}$. En el caso del jazz de ese país su musicalidad estaría dada, según Piedade, por una amalgama de musicalidades regionales que se sitúa vinculada a la del jazz de Estados Unidos. A esta relación dialéctica la denomina fricción de musicalidades, porque presenta movimientos tanto de tensión como de síntesis, de acercamiento o alejamiento. Según Piedade, esta metáfora mecánica implica que "los objetos en contacto tocan y frotan entre sí sus capas más externas, quizás intercambiando partículas, pero la sustancia más dura del núcleo tiende a ser preservada" 6 . Es decir, aunque el discurso de los músicos nativos se identifique con referencias identitarias a

1 Pujol 2004, Menanteau 2003, Piedade 2003, Corti 2009 y 2012a, Corti y Vera Cifras 2010, Ferreira y Corti 2013.

22005.

3 En los términos en que Carvalho y Segato (1994) refieren como musicopoiesis, los discursos musicales de primer grado que comprenden tanto al discurso propiamente musical en el acto de hacer música, como la participación de músicos y oyentes en la semiosis musical mediante la performance creativa y la recepción activa.

4 Corti 2007. Abundaré más adelante en esta relación entre identidad y música.

5 Piedade 2003: 53.

6 Piedade 2003: 54-55. 
tendencias musicales denominadas como brazuca -la más nacionalizada-, fusión, o $\mathrm{ECM}^{7}$, el tipo de funcionamiento de fricción aparece en todas ellas, tanto en el plano sonoro como el performático.

Álvaro Menanteau ${ }^{8}$, por su parte, propuso una inscripción del jazz de Chile dentro de las experiencias que históricamente han sido caracterizadas como de fusión, pero trascendiendo la conceptualización tradicional que las designa como las "síntesis más generales del jazz en combinación con cualquier otro estilo de música popular”. Su argumento está basado en que la práctica de la fusión en nuestros países excedería lo específico jazzístico debido a su relativa autonomía, gestada en el marco de condiciones localizadas y periféricas. Sugiere entonces repensar las categorías estilísticas por fuera de las instaladas como dominantes desde el discurso jazzístico hegemónico, para el cual la fusión resultaría algo así como todo lo que se relaciona con el jazz pero que no es jazz en un sentido estricto, o al menos, lo que hegemónicamente así se considera como canon jazzístico. En cuanto a las cuestiones de nacionalidad, califica al movimiento del jazz de su país de fines del siglo XX y comienzos del XXI como una "tercera etapa" del cultivo del jazz en Chile cuyo desarrollo "aún está abierto", lo que "nos deja instalado un cúmulo de preguntas y cuestionamientos, tales como la existencia de un jazz chileno o el determinar dónde radicaría la chilenidad en esta práctica local del jazz"9.

En Uruguay, según Luis Ferreira, ya desde la década de 1970 se inició un proceso de otorgamiento de "tintes locales al jazz" [...] pudiéndoselo entender "como un lenguaje con elementos en común y articulable musicalmente a otras maneras y estructuras locales, especialmente aquellas de matrices africanas como el candombe ${ }^{10}$. Ferreira propone acceder a este tipo de lenguaje jazzístico como una práctica multisituada que ha trascendido a Estados Unidos "porque hay músicos en todo el mundo que tocan no solamente las formas creadas históricamente en EUA por los afrodescendientes", sino que también "en muchos casos crean nuevas formas a partir de elementos y conocimientos musicales locales como parte de la diáspora africana en América del Sur y el Caribe"11.

7 Por el sello discográfico independiente de jazz contemporáneo y experimental de ese nombre.

82006.

9 Menanteau 2006: 141.

10 Ferreira y Corti 2013: 422. De este texto cito: "Candombe es la denominación que adquirieron las prácticas musicales de tambores y danza de los afrodescendientes en Uruguay, constituyendo el principal y más sonoro aspecto de la diáspora africana en el extremo sur del continente americano. Las llamadas de tambores, el desfile local durante la época de carnaval, cierra el ciclo de salidas de tambores que se producen durante todo el año, a cargo de grupos basados en tres tipos de tambores de duelas: chico (en registro agudo, con función de péndulo), repique (medio, improvisador, con función de regulador) y piano (bajo, con función de base y respondedor). En los inicios de la década de 1950 adoptó un patrón musical similar al de la clave afrocubana. La palabra candombe se encuentra también denominando prácticas musicales y rituales muy diferentes de afrodescendientes en Minas Gerais (Brasil) y en Argentina, aunque sin la popularidad masiva y regional alcanzada por el afrouruguayo ni su desarrollo musical polirrítmico e influencia en los géneros populares del Río de la Plata" (Ídem).

11 Ferreira y Corti 2013: 442. 
Para citar algunos otros ejemplos en esta revisión inacabada de los debates acerca de identidad y jazz en América Latina, resulta de interés el dato que el músico e investigador colombiano Rafael Serrano comentó acerca de que una de las puertas de entrada del jazz en su país haya sido la costa Atlántica y no la ciudad capital Bogotá, a donde llegaron los músicos desde ciudades como Cartagena a partir de fines de los años cuarenta. Desde entonces tres generaciones de artistas confluyeron en lo que aún calificando como "audaz", Serrano denomina un "renacimiento jazzístico" bogotano. Esto ocurrió gracias al espacio académico, los festivales y las iniciativas independientes que promueven el jazz en Colombia, que incluyó la consolidación de una nueva camada de músicos, pese a las difíciles condiciones políticas del país que provocan su éxodo.

En Venezuela, Simón Balliache ${ }^{12}$ sostiene que aun partiendo de la idea del jazz como una "música universal”, existiría una venezolanización del género que se produce cuando los "intérpretes logran tener factores comunes, tocan temas de compositores criollos, y a los géneros nacionales como el vals, el joropo y otros, se le adicionan bases jazzísticas para hacerlos parte del repertorio de todos los grupos”. Entre las corrientes del jazz venezolano el autor distingue a aquellas más "fieles al jazz proveniente de EE.UU. o de los que utilizan los ritmos del Caribe, y quienes se apoyan en el folclore". También adjudica a las generaciones de las décadas de 1980 y 1990 una diferencia basada en la búsqueda de un sonido propio que incluye "los componentes instrumentales nacionales cada vez con más frecuencia”, por lo que "es más fácil identificar cuándo un tema es ejecutado por una agrupación venezolana, aunque se encuentre enmarcado en cualquiera de las tendencias antes mencionadas".

Pepe Janeiro ${ }^{13}$, por su parte, reivindica una identidad del jazz en México que resultaría tan híbrida como la de su propio país: "como la naturaleza primera del jazz, México es un importante polo de mestizaje”, dice. Data los orígenes del jazz en México hacia 1920, cuando diversos pobladores, entre ellos los músicos, iban y venían de Nueva Orleans a distintas ciudades mexicanas. Por otra parte, si bien reivindica que "el jazz que se hace en México es el jazz mexicano", plantea la paradoja que señala que si bien es cierto "que no existe un movimiento nacionalista mexicano en terrenos del jazz [...] también es cierta la impronta del folclor nativo en la música jazz hecha en México"14.

Por otra parte se han producido intercambios, aunque de manera incipiente, que analizan el entrecruzamiento de experiencias entre distintos circuitos de la región. Por ejemplo, y en cuanto a la relación entre Argentina y Chile, "una mirada de cono sur, trasandina y especular" permitió "dar cuenta de un proceso de reconversión estética que se viene gestando en forma paralela" a ambos lados de los Andes posibilitando "la apropiación de formatos musicales tradicionalmente

\footnotetext{
121997.

132012.

14 Janeiro 2012: 348.
} 
considerados ajenos para la construcción de la propia identidad"15. Se ha podido constatar además que en los cien años de jazz en ambos países esta interrelación resultaría un producto del histórico intercambio -aunque con altibajos- de músicos para la realización de giras y grabaciones de discos, sobre todo en las décadas de los cuarenta y cincuenta y a principios del siglo XXI' ${ }^{16}$.

Un importante aporte resulta también el volumen recientemente editado que recoge los trabajos presentados en el congreso "El jazz desde la perspectiva caribeña" de 20117. En grandes líneas, este conjunto de debates permite la emergencia de fricciones diversas -como dice Piedade, aunque los casos aquí revisados refieran a cuestiones específicamente discursivas- que existen entre las narrativas historiográficas hegemónicas pertinentes al jazz, las conceptualizaciones varias que abordan las temáticas de música e identidad y que buscan desplazar los antiguas perspectivas esencializantes de nacionalización, y las historias que se están construyendo y reconstruyendo en torno al jazz de América Latina y el Caribe. Respecto de estos tópicos me detendré en lo que sigue de este trabajo mostrando también cómo aparecen en los resultados de un proceso de investigación específico en un ejemplo de jazz regional.

\section{DESAFÍOS PARA UN JAZZ LATINOAMERICANO}

Uno de los obstáculos que aparece como más visible para pensar el jazz de América Latina tiene que ver con la constitución misma del campo de investigación, ya sea por el disímil grado de interés que existe del jazz en los ámbitos académicos, o por las características específicas de la investigación musical en los distintos países de la región.

Esta cuestión es condición de posibilidad para la construcción de un marco conceptual común: la palabra jazz puede significar cosas muy distintas a lo largo de todo el continente y también dentro de un mismo país. Según qué abordaje de la música realicemos -lo que puede incluir la adscripción a distintas tradiciones musicales-, no es lo mismo pensar el jazz como un género estadounidense, afronorteamericano, afroamericano, como música negra, etcétera ${ }^{18}$.

Acceder a la identidad como atributo de la música -y de la música en términos generales y universales- tiene entre sus opciones más transitadas su abordaje en

15 Corti y Vera Cifras 2010: 187.

16 Menanteau 2006; Pujol 2004; Corti y Vera Cifras 2010.

17 Tejeda y Yunén 2012.

18 Ya en la década del sesenta en Estados Unidos, Amiri Baraka llamó la atención (por medio de un artículo en la revista especializada Down Beat), acerca de que todo lo que se había escrito referido al jazz no representaba más que una perspectiva "blanca", que carecía de una necesaria comprensión de la filosofía de la música negra (Baraka 2007: 71). En la actualidad el trompetista norteamericano Nicholas Payton promueve desde su blog la denominación "Black American Music", \#BAM, para reemplazar la categoría "jazz", a la que considera "una caricaturización blanca de la música negroamericana" (http:// nicholaspayton.wordpress.com). 
una condición de "nacionalizada". Desde esta mirada, el jazz sería "norteamericano" porque su origen ha sido histórica y hegemónicamente situado fronteras adentro del actual Estados Unidos de Norteamérica ${ }^{19}$. Se trata esta en realidad de una operación de construcción de sentido que localiza y adscribe identidades a territorios delimitados por el Estado nación, operación naturalizada desde la formulación de los nativismos decimonónicos hasta los nacionalismos del temprano siglo XX, que fueron los que ofrecieron sucesivos modelos sonoros de la nación, entre otros, el impuesto por Estados Unidos como potencia colonial ${ }^{20}$.

De acuerdo con este razonamiento, pensamos la identidad como un proceso de construcción simbólica que se despliega, por un lado, en forma de un enmascaramiento discursivo ${ }^{21}$ que funciona como significante para la advocación de una "identidad cultural", y que no es más que una expresión no problematizada de la autoridad y autenticidad derivada de la utilización de una definición unicista, estable y continua de la identidad ${ }^{22}$. Por otro lado, los sentidos identitarios no necesariamente narrativos -aunque también los hay de este tipo- también son producidos al interior de las prácticas musicales, intersectadas como musicopoiesis y enraizadas a su vez con los discursos sociales. Las identidades así creadas y sujetas a esas prácticas narrativas, sonoras y performáticas, son productoras de una significación asequible en la representación y siempre posicionada estratégicamente en relación con un poder, además de ser experimentadas y encarnadas en la performance ${ }^{23}$.

Dicho de otro modo, las identidades -más que la identidad-nunca podrían ser abordadas como lugar de sentido, sino más bien como procesos de producción de sentido(s) identitario(s) que nacionalizan, racializan o territorializan -entre otras opciones- las identidades sociales específicas. Y esto es así porque la música, como se ha dicho largamente, es un artefacto privilegiado de provisión de los diferentes elementos que se utilizan para la construcción de las identidades sociales ${ }^{24}$.

Esta perspectiva nos permite repensar los sentidos identitarios que se construyen en torno a los conceptos de nación y territorialidad, también para el jazz de la región. Como ya se dijo, estos son los mecanismos que funcionaron históricamente como legitimantes de determinadas músicas para que puedan ser consideradas jazz hacia adentro de Estados Unidos, y que a su vez invalidan a las que quedan por fuera de sus fronteras territoriales. En tal sentido, el jazz del Caribe y de los músicos caribeños en Estados Unidos - a priori, aunque luego

19 Esta es una de las razones más importantes por las que sería tan difícil hablar, por ejemplo, de un jazz argentino, chileno, etcétera.

20 Madrid 2010a: 228.

21 Carvalho y Segato 1994.

22 Hall 2003: 18. Por ejemplo, la que suele reivindicar a un género específico como constitutivo de una esencia identitaria con atributos de nacionalidad, como es el caso de la cueca en Chile.

23 Corti 2012b.

24 Vila 2000. 
por extensión a toda música de jazz creada por latinoamericanos- no es jazz a secas, sino latin jazz 25 .

\section{DESCONSTRUIR LATINIDADES}

En noviembre de 2011 se realizó en la Universidad Veracruzana en Xalapa, México, un programa de debate académico que formó parte del IV Festival Jazzuv de esa universidad, precediendo una nutrida e importante agenda de conciertos. La locación en el golfo de México y la cercanía con el Mar Caribe resultaron inmejorables para el intercambio fructífero y novedoso. Coordinado por Luc Delannoy, filósofo y escritor de varias obras de reflexión acerca del latin jazz ${ }^{26}$, el evento reunió investigadores de cuatro continentes que ofrecieron sus perspectivas posnacionales ${ }^{27}$, para pensar el jazz de manera descentrada, incluyendo las tan mentadas narrativas clásicas de origen y desarrollo del género.

Allí el dominicano Darío Tejeda colocó algunos de los temas que habían sido debatidos hacía pocos meses en el IV Congreso Internacional Música, Identidad y Cultura en el Caribe (MIC) bajo el nombre de "El jazz desde la perspectiva caribeña" (abril 2011, Santiago de los Caballeros, República Dominicana). Por ejemplo, la influencia de músicos mexicanos y caribeños en lo que se conoció como los orígenes del jazz en Nueva Orleans a inicios del siglo XX, pero también en las primeras formaciones de big band en Nueva York durante los años veinte ${ }^{28}$. Asimismo, aunque no en contradicción con lo anterior, Tejeda hizo hincapié en la necesidad de empezar a pensar al jazz o al llamado latin jazz como un patrimonio cultural y no como producto de la invención de un músico o músicos particulares $^{29}$.

Esta perspectiva propone nuevas miradas relativas al mito de origen mismo del jazz, cuya construcción narrativa suele situarse fronteras adentro de Estados Unidos. El argumento sería más o menos este: colocar el inicio del jazz -indistintamente y entre otras opciones tanto circa 1890 con el ragtime, o en 1917 con la primera

25 Luc Delannoy reivindica el término "jazz latino" en un sentido productivo: "no renunciamos al concepto, aunque sus contenidos los desbordan", porque se trataría de "una serie de ficciones; queremos un jazz latino que se mueva en sus márgenes en vez de en su centro, por cierto inexistente -insisto-" (Delannoy 2012: 41). Otro sentido -pero no contradictorio al anterior-sería el que propone Darío Tejeda, para quien el jazz latino "fue asimilado en algunas de las Antillas -y parcialmente en Brasil- como parte de una revalorización de las 'culturas negras' por citar un concepto que estuvo en boga hace algún tiempo" (ibid..: 80). Como toda conceptualización es siempre situada, por mi parte recuerdo los relatos de músicos argentinos que comentaban lo difícil que resultaba su inserción en el medio estadounidense porque se esperaba que interpretaran como propios los ritmos llamados latinos, denominación con que se conocían en realidad los ritmos caribeños.

26 ¡Caliente! Una historia del jazz latino (2001), Carambola. Vidas en el jazz latino (2005), y Convergencias. Encuentros y desencuentros en el jazz latino (2012).

27 Como dice Alejandro Madrid (2010a), concepto al que volveremos más adelante.

28 Tejeda 2011a. Tejeda relató la historia de James Reese Europe y su orquesta militar, de actuación en tiempos de la Primera Guerra Mundial, integrada al menos en una de sus mitades por músicos afroportorriqueños.

29 Tejeda 2011b. 
grabación de la Original Dixieland Jass Band- como grado cero, como diría Roland Barthes, de los movimientos musicales posteriores, deja toda anterioridad musical velada en la noche de los tiempos. Congo Square, Canal Street, y las habaneras, los tangos y las bambulas que iban y venían de puerto en puerto conformaban en realidad un mismo mundo, un ámbito que preexistió a la constitución de las naciones americanas. Este mundo, la región amplia y lábil que incluye al Caribe y al golfo de México, continúa a pesar de la fundación de los Estados nación, aunque notoriamente atravesado y reconfigurado por la construcción de estos como tales.

En esta línea, la musicóloga colombiana Ana María Ochoa se ocupó de señalar estas cuestiones en un artículo que reflexiona en torno a la tragedia del huracán Katrina en 2005, y del peso simbólico, social y cultural de Nueva Orleans en la música de jazz y viceversa. Por historia, cultura y actualidad Ochoa considera que esta ciudad, desde su fundación en 1718 y durante todo el período en que es reconocida como cuna del jazz, fue históricamente el "margen norte del Caribe" más que una parte del corazón cultural de Estados Unidos, y hace suya la perspectiva de la historiadora Gwendolyn Hall para quien Nueva Orleans es "la más africana de las ciudades [norte]americanas"30.

Por su parte, el historiador norteamericano Ned Sublette -cuya opinión fue compartida por el musicólogo cubano Danilo Orozco- ${ }^{31}$ sostiene que las ciudades de Veracruz en México, Nueva Orleans y La Habana constituían un mismo circuito que seguía la corriente del golfo de México. Esta perspectiva amplía aún más la impronta latina del jazz, por ejemplo en aquello que Sublette dice acerca de que "la única cosa que New Orleans no es, no importa cuánto le guste decirlo a los músicos de hoy en día en New Orleans, es ser la ciudad más norteña del Caribe. New Orleans está en el golfo de México, al igual que La Habana" ${ }^{2}$. Es de destacarse además que estas citas forman parte de un texto realizado con la participación del también historiador y productor cubano René López, en una tarea encargada por el programa cultural Jazz at the Lincoln Center dirigido por Wynton Marsalis, con motivo del programa de colaboración con el músico cubano Chucho Valdés en 2010. Es decir, la contranarrativa que descentra el origen nacionalizado del jazz como estadounidense es producida en la actualidad en el corazón mismo de la narrativa nacionalizada, al margen de la escasa circulación que pueda tener aún. Porque en realidad, como ha dicho Alberto Faya, músico y conductor radial de un

30 Ochoa 2006: 63. Según Ochoa, su "historia excepcional de ‘creolización’ que no terminó nunca de acomodarse al patrón americano de segregación” (Ochoa 2006: 66), se posiciona a contrapelo del discurso hegemónico que reivindica al jazz como una "inevitabilidad norteamericana" (según cita Taylor Atkins 2003: xii).

31 En conversaciones personales vía electrónica, a partir de una cuestión planteada en la lista de discusión de la rama latinoamericana de IASPM.

32 Sublette 2010: 6 . 
programa de jazz en la emisora Habana Radio: "si la historia hubiese sido diferente el jazz pudiera haber sido rumba o samba, son, cumbia o payada" 33 .

En sintonía con la argumentación de una zona de influencia del jazz que trasciende los límites nacionales, Raúl A. Fernández sostiene que la historia del jazz en Cuba es "prácticamente tan larga como la historia del jazz en Estados Unidos”, lo que le permitió desarrollar una tradición separada e independiente que fue llevada adelante por los músicos cubanos en el siglo XX. Tanto los expatriados como los residentes fundaron en su conjunto "un nuevo híbrido de híbridos, una mixtura del jazz y de la música afrocubana, que se convirtió en el género más excitante de todos los conocidos bajo el nombre de latin jazz"34.

La trilogía ;Caliente! Una historia del jazz latino (2001), Carambola. Vidas en el jazz latino (2005) y Convergencias. Encuentros y desencuentros en el jazz latino (2012) de Luc Delannoy aportó también una mirada sutilmente diferente de la idea de latin jazz, pero como jazz latino: "músicas cuyas formas se abren al mestizaje; música nómada que hace malabares con la sintaxis de las músicas que la enriquecen [...] música con identidades múltiples que salió de puertos como Nueva Orleans, La Habana, Nueva York o Buenos Aires ${ }^{35}$.

Otra opción estuvo constituida por la edición del libro Jazz en español. Derivas hispanoamericanas, que busca "pensar y presentar una música de la que se habla y escribe en el mismo idioma, con cientos de acentos diferentes" 36 . Se trata de una exhaustiva compilación de artículos que describen las escenas jazzísticas de once países (Argentina, Bolivia, Chile, Colombia, Cuba, Ecuador, España, México, Paraguay, Perú, Uruguay y Venezuela) y dos regiones (Caribe y América Central). La persistencia del coordinador de la obra y el interés que ha despertado suscitaron que además de la edición original de la Universidad Veracruzana en México se hayan sucedido otras en Sevilla (2015), Lima (2016) y La Habana (2018).

Por otro lado, el Grupo de Trabajo "Jazz en América Latina" de la Rama Latinoamericana de la Asociación Internacional para el Estudio de la Música Popular (IASPM-AL) lleva ya cuatro ediciones de simposios realizados en el marco de los congresos bienales de la asociación. Los dos primeros (Córdoba 2012 y Salvador de Bahía 2014) pusieron en común algunos estudios desarrollados en la región acerca de diversos aspectos de las escenas jazzísticas locales (su historia, su relación con la enseñanza y los circuitos culturales de las ciudades, los debates acerca de su legitimidad, etc.). El tercer simposio (La Habana, 2016) se dedicó a las experiencias de hibridación y los procesos de transculturación en los que interviene el jazz de la región. Y el cuarto simposio (San Juan de Puerto Rico, 2018) se ocupó de las cuestiones relativas al poder implicadas en la música y el jazz en particular, a escala continental y nacional. La mayor parte de las ponencias

33 En conversaciones personales vía electrónica, a partir de una cuestión planteada en la lista de discusión de IASPM-AL.

34 Fernández 2003: 3.

35 Delannoy 2012: 37.

36 Ruesga Bono, 2013: 8 
de investigadores de Argentina, Brasil, Chile, Colombia, Cuba, España, México, Puerto Rico, República Dominicana y Venezuela fueron editadas como artículos en las Actas de los citados congresos, los que se encuentran disponibles en la página web de la Asociación ${ }^{37}$.

Por supuesto que no se pretende establecer aquí la novedad de la consideración del jazz en su versión conocida como latina, sino más bien de sugerir cómo se está produciendo una relectura del término que sintoniza con las prácticas actuales y pasadas del jazz de la región.

Además de la obra del ya citado Luc Delannoy, de la profusa historia de la bibliografía en español que Julián Ruesga Bono expuso en 2010, y de la ya existente en inglés y otros idiomas, lo que se está advirtiendo con estas nuevas investigaciones es la condición posnacional de la música en general y del jazz en particular. ¿Qué quiere decir posnacional? Alejandro Madrid propone que sin negar la existencia de los Estados nación podemos adoptar otras perspectivas para acercarnos a la música, más allá de cánones fijos que atan identidades a territorios o a narrativas de nacionalidad, como por ejemplo las que surgen del análisis de las prácticas musicales y los complejos de performance. Podemos citar como ejemplos la propuesta de E. Taylor Atkins ${ }^{38}$ de pensar al jazz como un temprano agente de globalización de ida y vuelta entre metrópolis y periferias, en donde adquiere un nuevo sentido la reivindicación que realiza Delannoy ${ }^{39}$ de las historias de los artistas latinos que, por su importancia, aún aguardan un reconocimiento equivalente al de los nacidos en territorio norteamericano. O la percepción de este autor de aquello que subyace en los movimientos migratorios de los músicos, siempre atravesados por las circunstancias políticas y económicas de América Latina, y que constituye otro tipo de construcción de identidades no ancladas, móviles y flexibles ${ }^{40}$. El espacio de la creación como hecho cultural trasciende así los límites de la nacionalidad: el nomadismo hacia Estados Unidos y Europa da cuenta también de otros lugares de origen, aunque estos permanezcan imprecisos e inabarcables en las historiografías globales de los ámbitos metropolitanos, siendo al mismo tiempo reveladores de la gran variedad de prácticas musicales que suelen ser denominadas genéricamente como latin jazz.

Quisiera introducir aquí otra idea que resuena cuando pensamos en estos fenómenos, aquella que el sociólogo de origen británico y guayanés Paul Gilroy denomina Atlántico Negro ${ }^{41}$. Se trata de pensar a las músicas como formas culturales transnacionales, estereofónicas, bilingües o bifocales originadas con la esclavización de africanos que alimentó la constitución del capitalismo, y que luego se reconvirtieron y resignificaron con la expansión global de las industrias culturales en el siglo XX, en donde el jazz cumplió un rol importantísimo como mercancía

37 Sección del Grupo de Trabajo "Jazz en América Latina” en la web de IASPM-AL: [http://iaspmal. com/index.php/2016/03/07/jazz-al/]. Las actas del simposio de 2018 están en proceso de edición.

382003.

$392001,2005,2012$.

40 Delannoy 2005.

411993. 
cultural pero también como vehículo de canalización cultural y política de las más variadas comunidades artísticas del mundo ${ }^{42}$.

Esta perspectiva habilita otro tipo de miradas respecto de la historia del jazz a las que se suman otras que ya se están produciendo en la zona más austral del continente americano. Desde Uruguay, el músico y antropólogo Luis Ferreira encuentra un común "núcleo de sensibilidad" en las músicas de ese Atlántico Negro, en donde cada caso específico es una "forma particular de una sensibilidad polirrítmica más general" orientadora de la producción musical en las diversas locaciones del Oeste de África y Norte, Centro y Sudamérica. Esta sensibilidad está basada en el interés compartido por "una manera particular de interrelación de específicos patrones musicales", así como sucede en el candombe uruguayo o en la conga afrocubana. Y, además, cada una de estas manifestaciones particulares articulan situaciones de interacción musical entre los ejecutantes, los diversos contextos locales del "mundo del arte", y los procesos de constitución de los Estados nacionales y de implantación de sucesivos proyectos de modernidad, como resulta en el caso del swing del jazz, el groove del soul, el sabor de la salsa o la alegría del samba ${ }^{43}$.

La idea de Atlántico Negro debe incluir también una mirada acerca de los intercambios desde y hacia el Cono Sur, tarea que se encuentra en proceso actualmente. En este sentido, Luis Ferreira hace suyas las críticas de José Jorge de Carvalho en el sentido de que "una cultura atlántica negra bifocal" debe ser considerada plural por "constituirse en una geohistoria marcada por las asimetrías norte/sur" 44 .

\section{OTRA MIRADA EN EL ESPEJO}

La deconstrucción de las perspectivas nacionalizantes de la identidad nos permite repensar las narrativas identitarias no solo en cuestiones de nación y territorio, sino también en relación con las construcciones estilísticas que se asocian a la nacionalidad. Veamos un caso específico de investigación, aunque muy sintéticamente por razones de espacio, como el que realicé del jazz argentino, en donde se analizaron discursos nativos y prácticas musicales de los músicos en torno a identificaciones de territorialidad, nacionalidad y racialidad ${ }^{45}$. Tres aspectos básicos

42 Taylor Atkins 2003.

43 Ferreira 2005.

44 Ferreira 2008: 234. Para profundizar en estas cuestiones ver José Jorge de Carvalho 2002; Ferreira 2008; Guerreiro 2010. Esta última autora realiza en su reciente libro Terceira Diaspora una invitación a recorrer en imágenes, textos y músicas las diversas trayectorias simbólicas del Mundo Atlántico, partiendo de la ciudad de Salvador de Bahía como GPS.

45 Corti 2015. El programa de trabajo consistió en una tarea etnográfica realizada con músicos de diferentes alineamientos estéticos, pertenencias etarias o identificaciones culturales, que incluyó la realización y posterior análisis de entrevistas semiabiertas y de profundidad acompañadas por ejemplos musicales que buscaban mostrar los modos de imbricación del discurso musical y no musical. Me interesaron especialmente los discursos de racialización de la música de jazz y su relación con aquellos enfocados en temáticas de identidad y práctica musical. La selección de los artistas (agrupados 
fueron referidos por los músicos como modos de identificación que constituyen su experiencia: su propia música o musicopoiesis; sus referentes musicales; y los valores (estéticos, políticos) que estos referentes encarnarían, y que los músicos hacen suyos por medio de su trabajo artístico. La información recogida me permitió observar otros modos de organización de los discursos identitarios más allá de las categorías canónicas referidas a identidades fijas nacionalizadas, racializadas o estilísticas determinadas, en favor de otros ejes que se constituyen en cambio a partir de valores o ethos musicales y estéticos.

Este tipo de organización del discurso musical jazzístico (de y sobre la música) puede emparentarse con lo que Paul Berliner, a propósito de su trabajo respecto de músicos de jazz estadounidenses, denominó "constelaciones de rasgos y conceptos". Se trata del modo que utilizan los estudiantes de música para identificar conjuntos de músicos de una manera alternativa, en este caso en virtud de características en la sonoridad, la técnica o la personalidad, entre otras ${ }^{46}$. En similar dirección, siguiendo a Wittgenstein y la sugerencia de Míguez y Semán para el estudio de las culturas populares en antropología, Luis Ferreira realizó su propuesta relativa a la noción de "semblanzas de familia" que permite reconocer por su similitud una cierta "recurrencia parcial de rasgos comunes sin que reproduzcan una identidad exacta, pero que permite atribuírseles una misma 'ascendencia'" 47.

De esta forma, otras operaciones de sentido identitario que exceden los límites impuestos por las categorías de raza, nación y estilo, pueden ser identificadas a partir de rasgos comunes del discurso musical y no musical, valorados entonces según distintos modos de organización que pueden surgir de conceptos considerados claves, como swing, improvisación o libertad, por nombrar algunos, que refieren tanto (y a la vez) a competencias musicales como a modos ideológicos de concebir el mundo y el arte en particular. Por ejemplo, se es bueno si se tiene swing y está bueno tener swing, así como implicarse en una gran interacción colectiva, o desarrollar un estilo personal que se concibe libre, etcétera.

$\mathrm{Al}$ mismo tiempo, los referentes musicales cumplen un papel crucial en la organización de esta producción discursiva. Esto es descrito por Berliner como la capacidad para identificar los recursos estilísticos personales de los diferentes artistas, y que luego son organizados de manera cuasigenealógica en un continuum de tradición musical cuyas ramas principales están lideradas por aquellos que desarrollan un estilo personal, capaz de influenciar a otros y fundar escuelas estilísticas $^{48}$. De esta forma, el jazz se construye semióticamente sobre la base

en cinco conjuntos de tres y cuatro músicos cada uno por criterios que desarrollo más abajo), y su caracterización por estilo y referentes surge de percepciones obtenidas en diez años de observación y escucha musical en campo como producto de mi anterior actividad de producción de conciertos de jazz en el Jazz Club del Paseo La Plaza de Buenos Aires (1996-2000), y otros ciclos, como Jazz y Vinos en el Centro Cultural Konex (2002-2004), Jazz por Mujeres y Netizen Jazz Festival (2004), y Jazz Club (2005), además de entrevistas realizadas semanalmente durante el año 2002 en Radio Nacional.

46 Berliner 1994: 135

47 Ferreira, Romaniuk y Corti 2011: 93

48 Berliner 1994: 120-145. 
de "un patrón o una gramática de autocreación, autosuficiente, con reglas internas" que se regula a sí mismo refiriendo a la "entera tradición de la música negra" de acuerdo con Sean Singer ${ }^{49}$. Es decir, a medida que se evoca un referente determinado, se lo hace además a la cadena semiótica de la que forma parte, contribuyendo a definir la identidad del artista "como individuo, como miembro de la colectividad y como un eslabón en la cadena de tradición” ${ }^{0}$. Este sistema de significación se puede relacionar también (abonando la propuesta de Singer) a la capacidad de los músicos africanos de crear "en un balance a través del cual aprovechan la profundidad de la tradición, mientras que la revitalizan y adaptan a nuevas situaciones" 51 , en donde los tambores maestros cumplen el rol de organizadores del discurso ${ }^{52}$.

Para los músicos que hacen jazz en Argentina ese continuum de tradición musical excede, por supuesto, los límites del propio país. Emerge siempre en relación con un lugar otro cuya ubicación espacial y simbólica es muy difícil de precisar e incorporar, tanto por la conflictiva relación cultural que históricamente fluctuó respecto de la potencia imperial estadounidense como por la imposibilidad de situar al sí mismo en un contexto cultural negro ${ }^{53}$. En este marco, desde una mirada hacia adentro del campo artístico en el que se inscribe a sí mismo un artista en particular (entendiendo por campo artístico no solo a los músicos sino también a las audiencias y críticos), un determinado referente musical condensa simbólicamente y en primer término ciertos rasgos de adscripción a un estilo (como se lo denomina en términos convencionales, así como New Orleans, Swing ${ }^{54}$ o bebop), lo que luego es validado en la práctica musical. Pero en esa adscripción subyacen

49 Singer 1997: 1

50 Ellison 1964, apud Gilroy 1993: 79.

51 Chernoff 1979: 65.

52 Ibídem.: 69-70.

53 Corti 2011: 71-72. Al respecto, el jazz en Argentina ocupó durante casi toda su historia el espacio de la música negra, en términos de la expresión racializada que remite a lo africano y lo afroamericano. Este proceso no resulta simplemente (o solamente) de una lectura esencialista y biologizante de su supuesta identidad como género musical. Fue más bien el resultado de un trabajo; “work, en el sentido de trabajo de construcción social de la realidad” (Frigerio 2006: 81), que operó y aún opera en niveles micro y macrosociales para ubicar lo negro, lo afro, lo africano, por fuera de un imaginario nacional. El mito de la blanquedad argentina se construyó por sobre la narrativa de "desaparición" de la población negra como producto de su participación en guerras civiles y de la impiedad de las epidemias en las últimas décadas del siglo XIX. De esta forma, en el proyecto decimonónico (extendido hasta el siglo veinte) de una Nación Argentina no había lugar para argentinos negros, por lo que no es posible pensar lo negro como argentino, produciéndose una imposibilidad tanto de una mera condición mestiza como de la existencia misma de una cultura negra y a la vez argentina en el país (Corti 2010).

54 Aquí el término Swing refiere al estilo de las grandes bandas originado en la década del veinte y con apogeo en el período entre los años treinta y cincuenta, conocido como la Era del Swing. Las que primero se conocieron aquí fueron las versiones blancas popularizadas por el cine de Hollywood que interpretaban música bailable, también llamada comercial, como las de Glenn Miller, Tommy Dorsey o Benny Goodman. Aunque no tuvieron el mismo papel en la industria cultural, las orquestas de músicos negros como Duke Ellington o Count Basie hoy son reconocidas como las principales desde el punto de vista de su referencialidad artística. Para diferenciar el estilo del uso del término swing como concepto musical utilizamos la mayúscula en el primer caso y la minúscula en el segundo. 
también significaciones relativas a valores musicales y no musicales, los ethos que esos referentes encarnarían, y que resultan más útiles para establecer conexiones con otros sentidos culturales y sus condiciones de producción. Estas significaciones quedan veladas tras la mera ubicación de un referente en un lugar histórico de una línea de tiempo, entre otras razones porque no podría darse cuenta así de la recepción local de esa historización en donde participan, por ejemplo, las tensiones políticas, económicas y culturales con Estados Unidos así como esa imposibilidad negra a la que se hacía referencia más arriba.

Es decir, cuando un artista o grupo de artistas interpretan un repertorio o adoptan el estilo de una figura como, por ejemplo, Charlie Parker, John Coltrane o Miles Davis (pero también del "Cuchi” Leguizamón o Astor Piazzolla), no solo se está invocando a ese artista como referente estético, sino también como figura clave en una cadena de tradición a la que se incorpora, aun cuando las categorías canónicas acerca de la música no lo habiliten para ello, por no ser norteamericano, por no ser negro, etcétera.

Dando un paso más allá, si a su vez introducimos al análisis un punto de vista que abarque una escala transnacional, vemos también cómo el reconocimiento de referentes reafirma la posibilidad de pensar al jazz regional en el mundo atlántico negro, articulando su pertenencia a él.

En efecto, este reconocimiento de un determinado referente produce a su vez un nuevo mapa simbólico de trayectorias artísticas. A partir de las definiciones nativas de los músicos concernientes a su propia identidad, y utilizando como punto de partida el tipo de relación preponderante respecto de la llamada tradición o continuum de referentes (lo que implica la adscripción a algunos de estos en particular y, por consiguiente, los valores que les son asignados), es posible (re) construir analíticamente otra cadena semiótica de significaciones identitarias. Así, habrá quienes se reconocen en una tradición más africanizada, latinoamericana, nacionalizada o europea, con sus variantes de mezclas entre estas.

Si nos representamos un mapa imaginario de esos recorridos simbólico-artísticos de los artistas, veremos que estos se entrecruzan en espacios geográficos tanto comunes como no comunes, que organizan lo que propongo como sus trayectorias simbólicas según sus identificaciones nacionales y regionales. De este mapa surge además el tipo de adscripción a una tradición que se presenta delineada por la invocación de los referentes artísticos, sea esta preponderantemente africana, afronorteamericana, afroamericana, latinoamericana, argentina, europea, etcétera.

De esta forma podemos identificar tres nudos o líneas de sentido que reorganizan las trayectorias simbólicas de los músicos según valores, referentes y espacialidad (ver Figura 1).

A. Un eje que establece una relación privilegiada entre África y Estados Unidos, pudiendo incluir a Argentina (en línea __).

B. Un eje afroamericano, con extensiones a África y Europa (en línea ........).

C. Una trayectoria triangular Estados Unidos-Argentina-Europa (en línea _ _ ). 


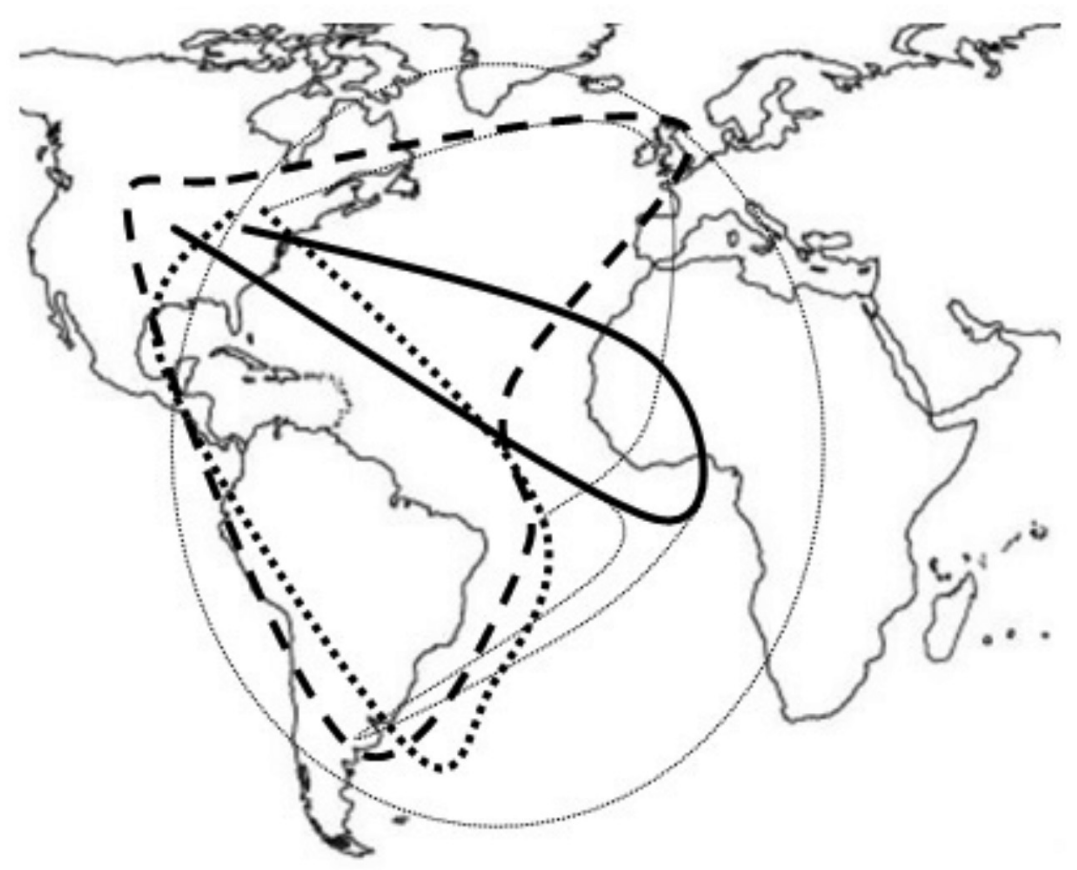

Figura 1. Mapa de trayectorias simbólico-artísticas de músicos argentinos de jazz.

Algunas observaciones que podemos realizar pertinente a este mapa tienen que ver con el peso simbólico que ocupan las distintas tradiciones musicales en el jazz argentino. En primer lugar, todas las trayectorias tienen en uno de sus extremos una confluencia en Estados Unidos: si bien esta podría resultar una afirmación prácticamente del sentido común, podría no existir de la misma manera si nos situáramos en Cuba como espacio de investigación.

La influencia europea, que a priori en Argentina podría ser considerada preponderante, no se destaca por su peso particular ni por prevalecer de las demás. Por el contrario, el lugar que ocupa África en la construcción de la tradición jazzística es todavía más relevante, constituyéndose como uno de los ángulos de una figura de tres lados que incluye a Estados Unidos y a Sudamérica.

Es llamativo el rol que ocupa este último y particular espacio regional, ya que la latinidad es relocalizada desde el tradicional centro caribeño hacia la conformación de una zona más abarcadora que comprende a Brasil y Uruguay, convirtiendo al latin jazz y a las músicas tradicionales de la región en diferentes aristas que conforman una región mayor. La mirada desde el sur logra entonces intervenir en el diálogo bidireccional Caribe-Estados Unidos. Por ejemplo, hacia adentro de Argentina, conversan la milonga y el candombe del Río de la Plata con los ritmos (llamados folklóricos, como chacarera o zamba) del Noroeste y sus conexiones con los mundos trasandino y afroperuano. 
Por último, si a su vez levantamos la vista de los detalles de ese mapa y miramos el conjunto, se deja ver por debajo un círculo central representado aquí con la línea de puntos, que se asemeja bastante a aquella idea del Atlántico Negro como espacio cultural productor de transición, intercambio, interacción y lucha, que relocaliza la historia del jazz argentino como parte de un movimiento transnacional mayor.

\section{CONCLUSIONES}

En muchas partes se están combinando el swing y las músicas tradicionales, las melodías populares y la improvisación, los instrumentos clásicos del jazz y los autóctonos de los distintos locales. Las múltiples hibridaciones producidas entre las expresiones originarias de América, las traídas al continente por los pueblos africanos esclavizados y las de las sociedades coloniales, así como sus posteriores reconversiones en música popular en donde jugó un rol crucial la industria cultural del siglo XX, son algunas de las expresiones conocidas como música instrumental en Brasil, fusión criolla en Chile o jazz y otras músicas en Argentina (entre otros ejemplos), que forman parte de la historia y práctica cultural de nuestras sociedades.

La práctica del jazz en las más diversas regiones de América Latina obliga a cuestionar sus narrativas nacionalizadas, posibilitando la apertura de ciertos tópicos discursivos que a fuerza de su reiteración llevan décadas de cristalización. Entre ellos, los relatos acerca del origen, los límites estilísticos, los mecanismos de legitimación y los imaginarios asépticos de la hibridez.

Los debates y ejemplos reseñados aquí son apenas una muestra de la creciente multiplicidad del jazz latinoamericano, lo que favorece la implosión de esas categorías canónicas. Una de sus consecuencias, entonces, es que no debiera ser tan difícil dejar de pensar en un solo jazz para en su lugar hablar de varios, como sucede con la música llamada erudita o con la diversidad de las conocidas como músicas del mundo.

También, el hecho de que muchos de los valores éticos y estéticos que organizan estas prácticas musicales sean compartidos en todo el continente, posibilita que su observación desde el hemisferio sur las inscriba como una manera más en que se construyen las formaciones culturales del Atlántico Negro. Es en este marco en que pueden ser leídos la tardía construcción del relato historiográfico del jazz de nuestros países, o los debates atinentes a jazz e identidad y su relación con las músicas de cada lugar o región.

Una historia del jazz también debería incluir todos estos nuevos relatos, como muestra de un siglo de expansión y afianzamiento de la música de jazz en esta zona del mundo, producida con toda la diversidad y riqueza de América Latina.

\section{BIBLIOGRAFÍA}

\section{Atkins, E. TAYlor}

2003 "Toward a Global History of Jazz". En Jazz Planet, editado por E. Taylor Atkins. Jackson: University Press of Mississippi, pp. xi-xxvii. 
Balliache, Simón

1997 Jazz en Venezuela. Caracas: Ballgrub.

BARAKA, AMIRI

2007 "El jazz y la crítica blanca". Parabólica, Revista de cultura contemporánea 5/5. Sevilla: Arte-facto Colectivo Cultura Contemporánea www.parabolica.net/parabolica_5. htm [Consulta: 20 de enero de 2009].

Berliner, Paul

1994 Thinking in Jazz. The infinite art of improvisation. Chicago: The University of Chicago Press.

Carvalho, José Jorge de

2002 "Las culturas afroamericanas en Iberoamerica: lo negociable y lo innegociable", en Cuadernos de Antropología 311, Universidad Federal de Brasilia, Brasilia, pp. 1-22.

Carvalho, José Jorge de y Rita Segato

1994 "Sistemas abertos e territórios fechados: para uma nova compreensão das interfaces entre música e identidades sociais”. Cuadernos de Antropología 164, Universidad Federal de Brasilia, Brasilia; http://dan.unb.br/multisites/dan/media/docs/ Serie164empdf.pdf; [Consulta 30 de noviembre de 2017].

Chernoff, John Miller

1979 African Rhythm and African Sensibility. Aesthetics and Social action in African Musical Idioms. Chicago and London: The Univeristy of Chicago Press.

Corti, Berenice

2007 'Identidad' del jazz argentino: cultura y semiótica de un discurso de interpelación. Tesina de licenciatura en Ciencias de la Comunicación. Buenos Aires: UBA.

2009 "Nuevos sentidos en el jazz argentino". En Entre la política y la gestión de la cultura y el arte. Nuevos actores en la Argentina contemporánea, compilado por Ana Wortman. Buenos Aires: Eudeba, pp. 273-287.

2010 "Discursos de raza y nación en y sobre Sarmiento. La (im) posibilidad mestiza de la 'blanquedad' porteña”. En Actas de las IJornadas de Estudios Afrolatinoamericanos (GEALA). Buenos Aires: Instituto de Estudios Históricos E. Ravignani, Facultad de Filosofía y Letras, pp. 1-14.

2012a “Argentina: Poéticas sonoras de la diversidad". En Convergencias. Encuentros y desencuentros en el jazz latino, editado por Luc Delannoy. México: FCE, pp. 349-361.

2012b Lo 'afro' en el jazz argentino: identidades y alteridades en la música popular. Tesis de Maestría. Buenos Aires: Facultad de Ciencias Sociales, Universidad de Buenos Aires.

2015 Jazz Argentino. La música "negra” del país “blanco". Buenos Aires: Gourmet Musical.

Corti Berenice y Vera Cifras, Miguel

2010 "La Cordillera Transparente: los nuevos circuitos de jazz en Chile y Argentina". En Por las huellas de la integración. Experiencias de la identidad y la diferencia, editado por Gloria María Hintz., Mendoza: Centro de Estudios Trasandinos y Latinoamericanos-Qelqasqa, pp. 187-194.

Delannoy, LuC

2001 ¡Caliente! Una historia del jazz latino, México: FCE. 
2005 Carambola, vidas en el jazz latino, México: FCE.

2012 Convergencias. Encuentros y desencuentros en el jazz latino. México: FCE.

FERnÁndez, Raúl A.

2003 "Si no tiene swing no vaya a la rumba", en Jazz Planet, editado por E. Taylor Atkins. Jackson: University Press of Mississippi, pp. 3-18.

Ferreira Makl, Luis

2002 Los tambores del Candombe. Buenos Aires: Colihue-Sepé.

2005 "Conectando estructuras musicales con significados culturales: un estudio sobre sistemas musicales en el Atlántico Negro”. En Actas del VI Congreso Latinoamericano de la Asociación Internacional para el Estudio de la Música Popular. Buenos Aires. Disponible en http://www.iaspmal.net/wp-content/uploads/2012/01/luisferreira.pdf [Consulta 30 de mayo de 2017].

2008 "Música, artes performáticas y el campo de las relaciones raciales. Área de estudios de la presencia africana en América Latina”, en Los estudios afroamericanos y africanos en America Latina. Herencia, presencia y visiones del otro, compilado por Gladys Lechini. Buenos Aires: CLACSO, pp. 121-156.

Ferreira Makl, Luis y Corti, Berenice

2013 "El jazz uruguayo en tres décadas del Hot Club de Montevideo", en Jazz en español: las escenas locales, editado por Julián Ruesga Bono. Sevilla: Arte-facto Colectivo Cultura Contemporánea / Veracruz: Jazzuv - Universidad Veracruzana, pp. 421-446.

Ferreira Makl, Luis, Romaniuk, Ana María y Corti, Berenice

2011 “'Lugares para aprender y lugares para practicar'. La transmisión del quehacer de la improvisación: algunos casos de la música popular en Argentina”. En ¿Popular, pop, populachera? El dilema de las músicas populares en América Latina. Actas del IX Congreso de la IASPM-AL, editado por Araújo Duarte Valente, Heloísa de; Hernández, Oscar; Santamaría-Delgado, Carolina y Vargas Herom. Montevideo: IASPM-AL y EUM. Disponible en http://www.iaspmal.net/ActasIASPMAL2010. pdf: pp. 86-98 [Consulta: 28 de mayo de 2011].

Frigerio, Alejandro

2006. “Negros' y ‘blancos’ en Buenos Aires: repensando nuestras categorías raciales”. En Buenos Aires Negra. Identidad y Cultura, compilado por Leticia Maronese. Buenos Aires: CPPHC, pp. 77-98.

Gilroy, Paul

1993 The Black Atlantic: Modernity and double consciousness. Cambridge: Harvard University Press.

Guerreiro, Goli

2010 Terceira diáspora. Culturas negras no mundo atlântico. Salvador da Bahia: Corrupio.

Hall, Stuart

2003 “Introducción: ¿quién necesita 'identidad'?”, en Cuestiones de Identidad Cultural, editado por Stuart Hall y Paul du Gay. Buenos Aires: Amorrortu, pp. 13-39.

Janeiro, Pepe

2012 "Jazz en México". En Convergencias. Encuentros y desencuentros en el jazz latino, editado por Luc Delannoy. México: FCE, pp. 337-348. 
Madrid, Alejandro

2010a "Música y nacionalismos", en A tres bandas. Mestizaje, sincretismo e hibridación en el espacio sonoro iberoamericano, editado por Albert Recasens y Christian Spencer Espinosa. Madrid: SEACEX y AKAL, pp. 227-235.

2010b Sonares dialécticos y política en el estudio posnacional de la música. Trabajo inédito presentado durante el XIX Congreso de la Asociación Argentina de Musicología, Córdoba, Argentina. 12 de agosto del 2010.

Menanteau, Álvaro

2003 Hacia una redefinición del término "fusión", fragmento de la ponencia presentada en el II Congreso de la Sociedad Chilena de Musicología, 17 de enero de 2003. Disponible en http://www.purojazz.com/articulos/articulos/redefinicion_fusion. html [Consulta: 15 de julio de 2006].

2006 Historia del Jazz en Chile. Santiago: Ocho Libros Editores [1a. edición 2003].

Ochoa, Ana María

2006 "Nueva Orleans, la permeable margen norte del Caribe". En Revista Nueva sociedad, ISSN 0251-3552, $\mathrm{N}^{\circ}$ 201, ejemplar dedicado a Cultura latina en Estados Unidos, pp. 61-72. Disponible en http://dialnet.unirioja.es/servlet/ articulo?codigo=1402230 [Consulta: 12 de julio de 2007].

Payton, Nicholas

2012 "On The European Influence In Black American Music...”. En sitio web Nicholas Payton, The Cherub speaks. Disponible en http://nicholaspayton.wordpress. com/2012/08/02/on-the-european-influence-in-black-american-music/. [Consulta: 10 de agosto de 2012].

Piedade, Acácio Tadeu de C.

2003 "Brazilian Jazz and Friction of Musicalities". En Jazz Planet, editado por E. Taylor Atkins. Jackson: University Press of Mississippi, pp. 41-58.

Pujol, Sergio

2004 Jazz al Sur. Historia de la música negra en Argentina. Buenos Aires: Emecé.

2005 "La impronta sonora: jazz, identidad y estilo", en Revista Todavía N ${ }^{\circ} 11$, Buenos Aires, agosto 2005. Disponible en http:/ / www.revistatodavia.com.ar/todavia27/11. pujolnota.html [Consulta: 2 de agosto de 2006].

RUESGA BoNo, JULí́N

2010 "Jazz en español: bibliografía de las escenas locales". En In-fusiones de jazz, editado por Julián Ruesga Bono. Sevilla: Arte-facto, Colectivo Cultura Contemporánea, pp. 261-274.

2013 Jazz en español: las escenas locales. Veracruz: Jazzuv - Universidad Veracruzana / Arte-facto Colectivo Cultura Contemporánea. [2015] Valencia: CulturArts Música - Generalitat Valenciana. [2016] Lima: Instituto de Etnomusicología - Pontificia Universidad Católica del Perú. [2018] La Habana: Casa de las Américas.

SERrano, RAFAEL

2002 “Los Arnedo: maestros del jazz en tiempos de éxodo", Revista Nómadas 16 (abril), pp. 143-160. 
SINGER, SEAN

1997 "Velocity of Celebration:Jazz and Semiotics", [En línea] En All About Jazz: New York. Disponible en http://www.allaboutjazz.com/articles/ac0297_02.htm [Consultado el 05/09/2006].

Sublette, Ned

2010 The Latin and the Jazz, en sitio web del programa Jazz at the Lincoln Center. New York: Jazz at the Lincoln Center. Disponible en http://jalc.org/cuba [Consulta: 7 de junio de 2011].

Tejeda, Darío

2011a El jazz: una perspectiva caribeña. Conferencia inédita presentada en el IV Festival Jazz. Universidad Veracruzana: Xalapa.

2011b Para qué una historia del jazz. Participación inédita presentada en la mesa redonda homónima del IV Festival Jazz. Universidad Veracruzana: Xalapa.

Tejeda, Darío y Yunén, Rafael

2012 El jazz desde la perspectiva caribeña. Memorias del IV Congreso Internacional Música, Identidad y Cultura en el Caribe. Santiago de los Caballeros: INEC-Centro LeónMinisterio de Cultura República Dominicana.

Vila, Pablo

2000 "Música e identidad. La capacidad interpeladora y narrativa de los sonidos, las letras y las actuaciones musicales", en Recepción artística y consumo cultural coordinado por Mabel Piccini, Ana Mantecón y Gabriel Schmilchuk. México: CONACULTA, INBA y CENIDIAP, pp. 350-360. 